\title{
Erratum to: Calculation of total energy expenditure in publications on physical activity energy by Yamada et al. in 2009 and 2013
}

\author{
Yosuke Yamada $^{1,5,6} \cdot$ Keiichi Yokoyama $^{1} \cdot$ Risa Noriyasu $^{1} \cdot$ Tomoaki Osaki $^{1}$ • \\ Tetsuji Adachi $^{2,7} \cdot$ Aya Itoi $^{3,8} \cdot$ Yoshihiko Naito $^{4}$. Taketoshi Morimoto ${ }^{5}$. \\ Misaka Kimura $^{5} \cdot$ Shingo Oda ${ }^{1}$
}

Published online: 26 April 2016

(C) Springer-Verlag Berlin Heidelberg 2016

\section{Erratum to: Eur J Appl Physiol (2009) 105:141-152 DOI 10.1007/s00421-008-0883-7; Eur J Appl Physiol (2013) 113:2461-2471 DOI 10.1007/s00421-013-2682-z}

In the calculation of total energy expenditure (TEE) in two publications (Yamada et al. 2009, 2013) a serious mistake has slipped in and therefore needs to be rectified. The correct TEE is 1.2 times higher than the published miscalculated TEE. The $\mathrm{CO}_{2}$ production rate $\left(r \mathrm{CO}_{2}\right)$, and TEE were miscalculated by the DLW method previously as:

$r \mathrm{CO}_{2}=0.4554 \times \mathrm{TBW}(\mathrm{g}) \times\left(1.007 k_{\mathrm{o}}-1.041 k_{\mathrm{d}}\right)$.

The miscalculated TEE $\left(\mathrm{kcal} \mathrm{day}^{-1}\right)=(3.9 / \mathrm{FQ}+1.1)$ $\times r \mathrm{CO}_{2}$.

Where TBW is total body water. They should be:

$\mathrm{TBW}(\mathrm{mol})=\mathrm{TBW}(g) / 18.02$

The online version of the original articles can be found under doi:10.1007/s00421-008-0883-7, doi:10.1007/s00421-013-2682-z.

Yosuke Yamada

youtaro0831@yahoo.co.jp; yyamada831@gmail.com

Shingo Oda

m54899@sakura.kudpc.kyoto-u.ac.jp

1 Laboratory of Sports Science and Human Motor Control, Graduate School of Human and Environmental Studies, Kyoto University, Yoshidanihonmatu, Sakyo-ku, Kyoto 606-8501, Japan

2 Department of Medical and Sport Sciences, Kyoto Interdisciplinary Institute of Community Medicine, Kyoto, Japan

3 Department of Human Life Studies, Kobe Women's Junior College, Hyogo, Japan $r \mathrm{CO}_{2}\left(\mathrm{~mol} \mathrm{day}^{-1}\right)=0.4554 \times \mathrm{TBW}(\mathrm{mol})$

$$
\times\left(1.007 k_{\mathrm{o}}-1.041 k_{\mathrm{d}}\right)
$$

$r \mathrm{CO}_{2}\left(\mathrm{~L} \mathrm{day}^{-1}\right)=22.4 \times r \mathrm{CO}_{2}\left(\mathrm{~mol} \mathrm{day}^{-1}\right)$.

The correct TEE $\left(\mathrm{kcal} \mathrm{day}^{-1}\right)=(3.9 / \mathrm{FQ}+1.1) \times r \mathrm{CO}_{2}$ $\left(\mathrm{L} \mathrm{day}^{-1}\right)$.

Thus, the correct TEE is proportional to 1.2 times (22.4/18.02) higher than the miscalculated TEE. Presentation of the calculation of the correction factor of 1.2. The miscalculated TEE was used to estimate the physical activity level (PAL). With the corrected TEE, the average PAL increases from the originally reported 1.66 to 1.97 . This corrected average PAL is substantially higher than other published values (Blanc et al. 2004; Speakman and Westerterp 2010). The correlation coefficients between variables are not affected because the miscalculation is proportional to a constant.

4 Department of Food Science and Nutrition, School of Human Environmental Science, Mukogawa Women's University, Hyogo, Japan

5 Laboratory of Sports and Health Science, Kyoto Prefectural University of Medicine, 465 Kajii-cho, Kamigyo-ku, Kyoto 602-8566, Japan

6 Japan Society for the Promotion of Science, Tokyo, Japan

7 Osaka University of Health and Sport Sciences, Osaka, Japan

8 Department of Health, Sports and Nutrition, Faculty of Health and Welfare, Kobe Women's University, Kobe, Japan 


\section{References}

Blanc S et al (2004) Energy requirements in the eighth decade of life. Am J Clin Nutr 79:303-310

Speakman JR, Westerterp KR (2010) Associations between energy demands, physical activity, and body composition in adult humans between 18 and 96 y of age. Am J Clin Nutr 92:826834. doi:10.3945/ajen.2009.28540
Yamada Y et al (2009) Light-intensity activities are important for estimating physical activity energy expenditure using uniaxial and triaxial accelerometers. Eur J Appl Physiol 105:141-152. doi:10.1007/s00421-008-0883-7

Yamada Y et al (2013) Association between lifestyle and physical activity level in the elderly: a study using doubly labeled water and simplified physical activity record. Eur J Appl Physiol 113:2461-2471. doi:10.1007/s00421-013-2682-z 